\title{
A METODOLOGIA DE PROJETOS, A APRENDIZAGEM SIGNIFICATIVA E A EDUCAÇÃO AMBIENTAL NA ESCOLA
}

\section{THE PROJECT METHODOLOGY, THE MEANINGFUL LEARNING AND ENVIRONMENTAL EDUCATION IN SCHOOL}

\author{
Marilyn A. Errobidarte de Matos
}

CCET -Mestrado em Ensino de Ciências - Universidade Federal de Mato Grosso do Sul

\begin{abstract}
Resumo
Este trabalho é produto de uma investigação sobre metodologia de projetos e aprendizagem significativa, tendo como objetivo viabilizar uma aprendizagem significativa de conceitos inerentes às Ciências no contexto da Educação Ambiental. Neste artigo, descreve-se uma metodologia de projeto de trabalho desenvolvida para a "comemoração" do dia mundial do meio ambiente em uma escola municipal em Campo Grande, Mato Grosso do Sul, envolvendo alunos de sétimos e oitavo anos do ensino fundamental. Os resultados demonstraram que a metodologia empregada foi eficiente para que ocorresse aprendizagem significativa nos alunos.
\end{abstract}

Palavras Chave: metodologia de projetos, aprendizagem significativa, educação ambiental

\begin{abstract}
This work is a product of investigation on project methodology and Ausubel meaningful learning, with the aim of achieving a meaningful learning of inherent to science concepts in the Environmental Education context. In this article, it describes a methodology for projects of work developed for the "celebration" of the World Environment Day in a municipal school in Campo Grande, Mato Grosso do Sul, involving students of seventh and eighth years of the basic education. The results showed that the methodology used was efficient to have meaningful learning by students.
\end{abstract}

Key words: project methodology, meaningful learning, environmental education

\section{INTRODUÇÃO}

No início do séc. XX, diante das novas necessidades de aprendizagem dos educandos no cotidiano escolar, os filósofos John Dewey e William Heard Kilpatrick,, propuseram uma nova concepção de educação - a Pedagogia Ativa (atual Pedagogia de Projetos), que em síntese, versava sobre uma prática pedagógica onde o aluno era sujeito de seu próprio conhecimento, embasado pela aplicação de projetos no contexto 
escolar, visando evidenciar as experiências de vida adquiridas. (LEITE, 1996). Sendo assim, o método de projetos, na visão desses dois filósofos, são tidos como a base para a luta por uma educação progressista. No Brasil a discussão sobre pedagogia de projetos iniciou-se na década de 30, com Anísio Teixeira e Lourenço Filho, ambos idealistas da Escola Nova.

Hoje essa concepção de educação recebe denominações variadas, tais como: projetos de trabalho, metodologia de projetos, metodologia de aprendizagem por projetos e pedagogia de projetos e tem como principais estudiosos César Coll, Josette Jolibert e Fernando Hernández. Apesar de várias denominações, essa concepção de educação, independente do nome, versa sobre a importância de se considerar a participação ativa do educando no processo ensino-aprendizagem através da pesquisa. Haja vista que sua prática significa "uma maneira de entender para compreensão, o que implica um processo de pesquisa que tenha sentido através de diferentes estratégias de estudo. Projeto é uma concepção de como se trabalha a partir de pesquisa" (HERNÁNDEZ, 1998)

A idéia fundamental dos projetos como forma de organizar os conhecimentos escolares e que os alunos se iniciem na aprendizagem de procedimentos que lhes permitam organizar as informações, descobrindo as relações que podem ser estabelecidas a partir de um tema ou um problema. O professor é um facilitador, favorece, recolhe e interpreta as contribuições dos alunos, no entanto, é ser ativo, criativo e crítico que contrasta as suas intenções com sua prática.

Segundo Dewey, um projeto prova ser bom se for suficientemente completo para exigir uma variedade de respostas diferentes dos alunos e permitir, a cada um, trazer uma contribuição que lhe seja própria e característica. Essas respostas são resultados de uma aprendizagem significativa de conceitos, adquirida pelo aluno durante o processo de ensino e aprendizagem (GERIR, 2003). Numa abordagem construtivista Ausubeliana, a aprendizagem significativa caracteriza-se pela interação entre o novo conhecimento e o conhecimento prévio. Nesse processo, que é não-literal e nãoarbitrário, o novo conhecimento adquire significados para o aprendiz e o conhecimento prévio fica mais rico, mais diferenciado, mais elaborado em termo de significados, e adquire maior estabilidade. (MOREIRA, 1999)

Este trabalho é o produto de uma investigação sobre metodologia de projetos e aprendizagem significativa, tendo como objetivo viabilizar uma aprendizagem significativa de conceitos inerentes as Ciências no contexto da Educação Ambiental. 
Trataremos aqui fundamentalmente da metodologia de projetos de trabalho desenvolvida para a "comemoração" do dia mundial do meio ambiente em uma escola municipal em Campo Grande, Mato Grosso do Sul, envolvendo alunos de sétimos e oitavo anos do ensino fundamental.

O projeto focalizado partiu da necessidade de se desenvolver na escola atividades significativas em datas pontuais, considerando que as datas comemorativas são previstas no calendário escolar e normalmente são comemorações isoladas e descontextualizadas, apenas lembrando algum fato, e na maioria das vezes se torna "festa", sendo o aluno sujeito passivo no processo.

\section{METODOLOGIA}

Participaram desta pesquisa 52 alunos de duas salas de sétimos anos e 25 alunos de oitavo ano, do ensino fundamental de uma escola municipal da cidade de Campo Grande MS. As atividades desta pesquisa foram desenvolvidas durante o período de quatro semanas, abrangendo duas aulas semanais de 60 minutos (em cada turma), no primeiro semestre do ano letivo de 2007, sua estrutura envolveu seis etapas:

i) abrangência do tema;

ii) escolha dos subtemas;

iii) problematização;

iv) pesquisa, sistematização e produção;

v) divulgação dos resultados;

vi) avaliação

Na primeira etapa, Abrangência do tema, fez-se uma reunião com cada sala, começando com uma breve apresentação sobre o dia mundial do meio ambiente, e solicitou-se aos alunos que se manifestassem sobre o que sabiam a respeito de meio ambiente.

A segunda etapa, escolha dos sub-temas, as salas foram divididas em grupos de até 5 alunos, e então cada grupo propôs um sub-tema para pesquisar, nessa etapa o professor deixou claro que os conteúdos trabalhados seriam os previstos nas Diretrizes Curriculares, portanto os conteúdos seriam adequados ao sub-tema e este ao tema meio ambiente. 
Na terceira etapa, problematização, os alunos expressaram suas idéias, crenças, conhecimentos e questões sobre o sub-tema escolhido. Terminada a etapa de problematização, iniciamos a quarta etapa, pesquisa, sistematização e produção, nesta fez-se necessário a mediação do professor, pois aqui os alunos desenvolveram os questionamentos elaborados na problematização.

A última etapa, avaliação, os alunos foram avaliados durante todo o processo, utilizou-se também uma avaliação coletiva e também uma auto-avaliação.

Para se obter a interpretação dos dados utilizou-se da pesquisa qualitativa, e os instrumentos de avaliação utilizados foram: observação, análise e teste. A metodologia aqui descrita foi desenvolvida nas aulas de Ciências, tendo sua culminância (divulgação dos resultados) no dia mundial do meio ambiente.

\section{RESULTADOS E DISCUSSÃO}

Iniciando a primeira etapa com uma discussão, procurou-se coletar as concepções sobre meio ambiente e também os conhecimentos prévios dos alunos. Nesta etapa ficou evidente que a maioria tinha uma visão antropocêntrica de meio ambiente. Já nesta etapa optou-se por iniciar os alunos na pesquisa, eles então teriam que procurar em diferentes fontes definições de meio ambiente e apresentar para o professor e os colegas. Com a apresentação de várias definições de meio ambiente, algumas ainda equivocadas, o professor mediou a discussão e os equívocos foram desfeitos.

$\mathrm{Na}$ segunda etapa, os sub-temas escolhidos pelo sétimo ano A foram: Dengue e Leishmaniose, no sétimo ano B: poluição atmosférica, sonora, visual, do solo e das águas e no oitavo ano: transgênicos, agricultura sustentável, agrotóxicos, aproveitamento dos alimentos e lixo orgânico. Nesta etapa, o professor aproveitou a experiência social dos alunos para discutir aspectos da realidade e possibilitar o confronto entre as suas próprias visões de mundo com outras visões de mundo, efetuar trocas de experiências entre o grupo, fazer análises de suas concepções sob outros pontos de vista, provocando, assim, o questionamento de suas próprias idéias e atitudes. Foi uma maneira de desafiá-los a atuarem como sujeitos ativos de sua aprendizagem.

$\mathrm{Na}$ etapa de problematização, surgiram perguntas, como exemplos do sétimo ano A: a) a Dengue e a Leishmaniose são doenças que ocorrem em todos os países? b) Elas são doenças ligadas à falta de preservação ambiental? c) A educação ambiental pode mudar o quadro da Dengue? d) Temos mesmo que sacrificar os cães com 
Leishmaniose? e) Essas doenças sempre existiram? f) O desmatamento contribui para a proliferação dos mosquitos? g) São os mesmos mosquitos?

Algumas perguntas que surgiram no sétimo ano B: a) Como podemos definir poluição atmosférica? b) O que é considerado poluição? c) Quando eu posso considerar poluição sonora? d) O que mede o som? e) Existe alguma legislação sobre poluição sonora? f) O que é poluição visual? g) A poluição do solo pode ser provocada pela natureza ou só é considerada poluição quando o homem atua? Alguns questionamentos do oitavo ano: a) O que é agricultura sustentável? b) Uma agricultura sustentável beneficia o meio ambiente? c) O que é agrotóxico? d) Existe agrotóxico que mata só um tipo de praga? e) Os agrotóxicos são tóxicos para as pragas e/ou para o homem? f) $\mathrm{O}$ que são transgênicos? g) Os alimentos industrializados que tem transgênicos em sua composição especificam o uso destes nos rótulos? h) Podemos comer transgênicos sem saber? i) É verdade que os transgênicos causam câncer? j) Podemos relacionar alimentação com meio ambiente? 1) O que é lixo orgânico? m) Como podemos aproveitar o lixo orgânico?

Com a disponibilidade de um laboratório de informática na escola, com internet, a maioria das pesquisas foi feita nesse meio, no entanto alguns contribuíram trazendo para a sala livros, revistas e panfletos, principalmente relacionados à Dengue, já que a cidade de Campo Grande teve sérios problemas com grande número de casos positivos.

Percebeu-se que os alunos tinham dificuldade em selecionar as informações da internet, um dado importante nesta etapa é a intervenção do professor, que traz maior riqueza às discussões e o seu confronto favorece o exercício da autonomia e da responsabilidade no educando, pois dele depende sua própria aprendizagem.

\section{Divulgação dos Resultados}

A divulgação dos resultados do Projeto de Trabalho tem como objetivo socializar o conhecimento produzido pelo grupo, neste caso, a divulgação foi no dia mundial do meio ambiente (05 de junho). Muitas são as formas de divulgar o trabalho, no entanto, optou-se em respeitar os limites de cada indivíduo, assim como suas habilidades.

O sétimo ano A produziu um teatro de fantoches sobre a Leishmaniose (Fig. 1), no texto ficou evidente a aprendizagem significativa de conceitos, ou seja, as palavras combinam-se comumente para formar sentenças e constituir proposições que representam realmente conceitos e não objetos. Esse tipo de aprendizagem é 
substantiva, ou seja, o conteúdo aprendido de uma forma significativa é explicado com suas próprias palavras (Ausubel et al,1980). Nele os alunos relacionaram vários conceitos novos com fatos cotidianos.

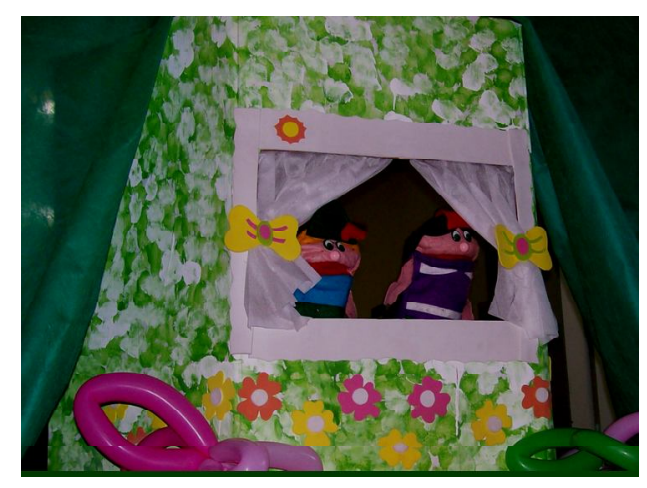

Figura 1 - Teatro de fantoches

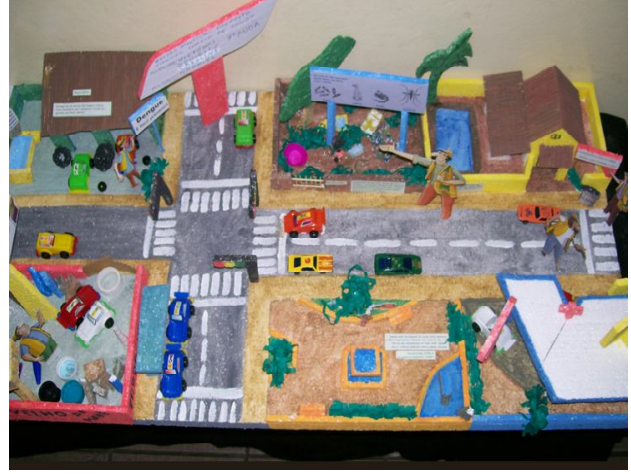

Figura 2 - Maquete sobre a Dengue

Um outro grupo da mesma série produziu uma maquete (Fig.2) representando um bairro com vários locais propícios ao desenvolvimento das larvas do $\underline{\text { Aedes aegypti}}$. O mais significativo nesse trabalho foi a preocupação dos alunos em reforçar os cuidados com o ambiente, em cada ponto da maquete tinha um "outdoor" com informações sobre a Dengue.

O Roletrando sobre a Dengue e Leishmaniose (Fig.3), foi um jogo desenvolvido com perguntas e respostas, nesse jogo o jogador rodava uma roleta que indicava se a pergunta seria sobre a Dengue ou a Leishmaniose, respondia-se a pergunta, em caso de acerto, marcava-se um ponto e ganhava-se o direito de jogar novamente. Em caso de erro, dever-se-ia passar a vez para o outro jogador. Para elaborar as perguntas e as respostas do jogo, os alunos necessariamente tiveram que associar vários conceitos, propor uma hierarquia destes, comparar as informações e expressar os significados de diversas maneiras.

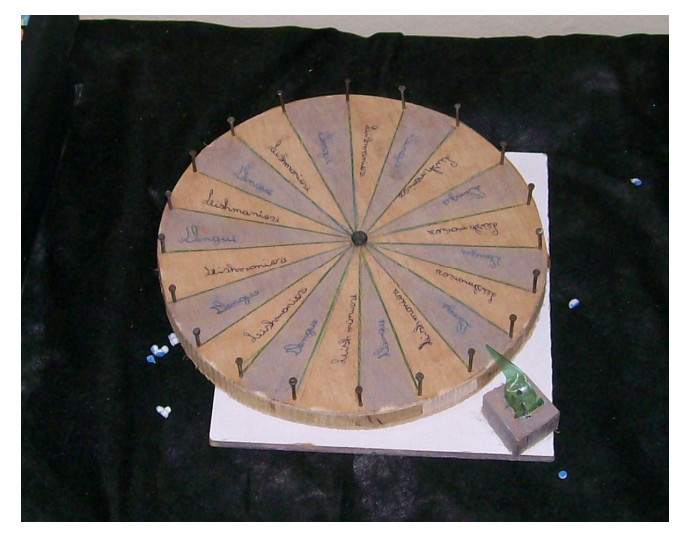

Figura 3 - Roletrando

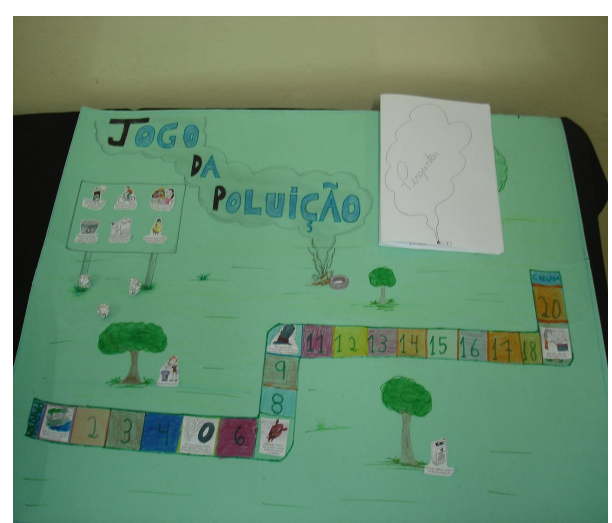

Figura 4 - Jogo tipo trilha 
O sétimo ano B produziu um jogo de tabuleiro tipo trilha (Fig. 4) sobre a poluição, com perguntas e respostas relacionadas aos vários tipos de poluição. Um jogo de Joken-pô com as mesmas regras deste, mas com um enfoque sobre a poluição atmosférica e várias maquetes demonstrativas, comparando ambientes preservados e poluídos foram também elaborados. Além disso, um outro grupo escreveu uma peça de teatro abordando a poluição sonora. $\mathrm{Na}$ representação teatral, vários assuntos foram abordados, como a legislação, o respeito ao outro, a unidade de medida do nível sonoro (decibel) $\mathrm{dB}$ etc. $\mathrm{O}$ assunto abordado merece destaque porque foi o que mais gerou dúvidas nos alunos, sendo que estas foram sanadas durante o processo de pesquisa e escrita da peça.

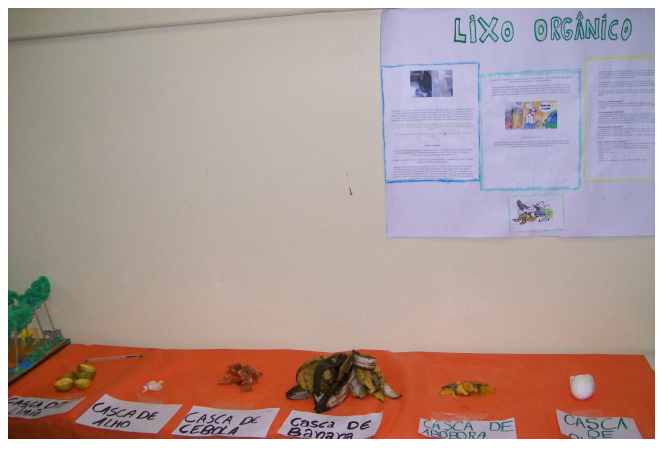

Figura 5 - Lixos orgânicos

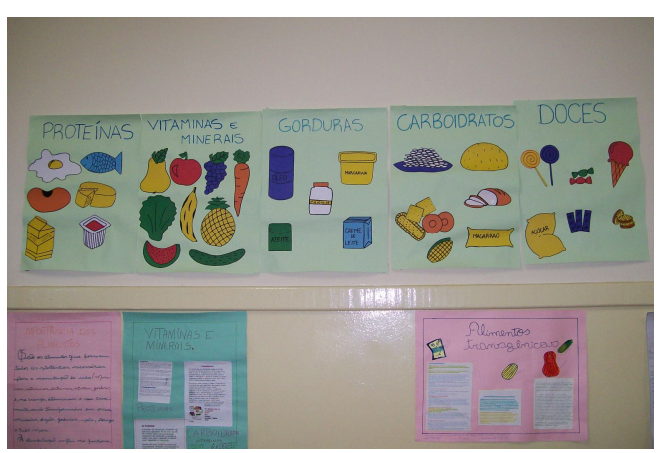

Figura 6 Cartazes sobre alimentação

Os alunos do oitavo ano produziram vários cartazes, textos e uma seleção de lixos orgânicos. Essa série apresentou uma discussão bem elaborada em sala de aula, onde cada grupo apresentou seu trabalho, permitindo-se ser questionado pelos colegas, potencializando, dessa forma, o aprendizado.

Para medir a eficiência da metodologia, aplicou-se um teste com questões dissertativas em todas as séries, onde os conceitos aprendidos durante $\mathrm{o}$ desenvolvimento do projeto foram aplicados em várias situações diferentes.

\section{CONSIDERAÇÕES FINAIS}

A metodologia de projetos rompe com o tradicionalismo do ensino, apontando para um professor mais reflexivo, com uma postura pedagógica que reflete uma concepção de conhecimento como produção coletiva. Essa concepção de ensino permite ao aluno "testar" seu aprendizado ao longo do projeto, ele mesmo reconstrói seus conceitos a cada etapa, relacionando o novo com idéias preexistentes na sua estrutura 
cognitiva e transformando os conceitos em proposições. O teste demonstrou que a metodologia de projetos foi eficiente para que ocorresse aprendizagem significativa nos alunos.

Percebeu-se também o desenvolvimento da autonomia nos alunos à medida que pesquisavam em fontes diversas, bem como o interesse em buscar respostas aos questionamentos, sem a solicitação do professor. Também a autonomia do professor, que ao assumir um projeto deixa de seguir o currículo "engessado" que é comum nas escolas.

\section{AGRADECIMENTOS}

Ao Prof. Dr. Adilson Beatriz (UFMS) pelas sugestões e à Fundação de Apoio ao Desenvolvimento do Ensino, Ciência e Tecnologia do Estado de Mato Grosso do Sul, (FUNDECT) pelo apoio financeiro.

\section{REFERÊNCIAS BIBLIOGRÁFICAS}

AUSUBEL, D; Novak, J; Hanesin, Helen; Psicologia Educacional. Rio de Janeiro. Editora Interamericana Ltda. 1980.

GERIR, Pedagogia de Projetos, Salvador, v.9, n.29, p.17-37, jan./fev.2003. Disponível em: http://www.liderisp.ufba.br/modulos/pedagproj.pdf . Acesso em 21 de set. 2007

HERNANDEZ, Fernando; VENTURA, Montserrat. A organização do currículo por projetos de trabalho. Porto Alegre: Artmed, 1998.

LEITE, L. H. A.; OliVEIRA, M. E. P. de; MALDONADO, M. D. Projetos de trabalho. In: BRASIL. Ministério da Educação e do Desporto. Secretaria de Educação à Distância. Diários: projetos de trabalho. Brasília: MEC/SEED, 1998. p. 57-98. (Cadernos da TV Escola. PCN na Escola; n. 3). Disponível em: http://www.mec.gov.br/seed/tvescola/pdf/diarios.pdf. Acesso em: 21 de set. 2007.

MOREIRA, Marco Antônio, Aprendizagem Significativa. Brasília. Editora da UnB, 1999 